\title{
Impact of HIV/AIDS on Education and Poverty
}

\section{By Nelson Ijumba}

South Africa has the largest number of children orphaned or made vulnerable by HIVIAIDS. In the face of AIDS, poverty, and violence, education is a precious right for the children of KwaZulu-Natal, South Africa. (C) UNICEF/Khumalo

\author{
While the causality between poverty and HIV is not clear, it is certain that HIV pushes \\ households and individuals into poverty.
}

2011 marks the thirtieth anniversary of the first report of HIV, which came from the United States, where cases of an unusual disease were seen among young gay men. Thirty years later, the location and pace of the epidemic has changed dramatically. Globally, an estimated

33.3 million people are infected or living with HIV, of which 22.5 million are in sub-Saharan Africa. In addition, of the

2.5 million children in the world estimated to be living with HIV, 2.3 million are in sub-Saharan Africa. Southern Africa, the most affected region, includes a number of middle- and lower-middle-income nations known as the hyperendemic countries. In South Africa alone, there are about 5.7 million people living with HIV/AIDS. In Swaziland, 42 per cent of women attending antenatal clinics are infected, with similar rates found elsewhere in the region. Many children are affected by the disease in a number of ways: they live with sick parents and relatives in households drained of resources due to the epidemic, and those who have lost parents are less likely to go to school or continue with their education.

Studies in the regions of Southern Africa and South-East Asia have found HIV/AIDS to negatively impact both the demand for and supply of education. ${ }^{1,2}$ Orphaned children are either pulled out of school or not enrolled at all due to the financial constraints of their affected families, and have to assume responsibilities of heading or providing for households. In this respect, girls are more vulnerable. In Kenya, links were found between parental deaths and children's progress through school. In Tanzania, households that have experienced an adult death have been found to delay the enrolment of younger children in school, but try to keep older children enrolled. In Malawi, it has been shown that the death of an adult encourages children to marry earlier, drop out of school to help support the family, and take on informal labour schemes. In Zambia, it is estimated that more than 7 per cent of approximately two million households are headed by children. ${ }^{1}$ The reduction in primary school enrolment has a domino effect on secondary and post-secondary enrolments as well. A 1992 World Bank study in Tanzania showed that HIV/AIDS was likely to reduce the number of primary and secondary school children by 22 and 14 per cent respectively. 1 The high infant mortality rate due to HIV/AIDS also reduces the number of children in school. The impact of HIV/AIDS on school teachers in terms of mortality, productivity, and costs has negatively affected the quality and availability of education. It is estimated that in 2015, nearly eight thousand teachers in the Greater Mekong Subregion will have died of AIDS, and six thousand will be HIV-positive. ${ }^{2}$ In Malawi, the rate of infection among teachers was higher than 30 per cent, with more than four teachers dying per day due to AIDS. ${ }^{1}$

A recent study in South Africa on HIV/AIDS in the higher education sector has shown that the mean HIV prevalence for students was 3.4 per cent, while the mean prevalence among the academic staff was about 1.5 per cent. 3 The prevalence levels are much lower compared to the general population. Since Higher Education 
Institutions (HEIs) are reservoirs for future leaders and professionals, it is essential that they adopt strategies of lower prevalence, with no new infections.

The economic impact of HIV/AIDS presents huge challenges. While the causality between poverty and HIV is not clear, it is certain that HIV pushes households and individuals into poverty. While many illnesses create catastrophic expenditures which can result in poverty, HIV/AIDS is among the worst because its victims are ill for a prolonged period of time before they die, and many are the chief household income earners.

In Southern Africa, however, HIV/AIDS is a disease of poverty. Here it is clear that poor people are most likely to be infected. The first and worst impact of HIV/AIDS on poverty is at the individual and household level. The effect then aggregates, influencing the macroeconomy through impacts on labour markets, and consequently the allocation of resources by governments. ${ }^{4}$ In a study on HIV/AIDS in rural Thailand, Michael P. Cameron identifies a vicious poverty-HIV/AIDS cycle in which HIV-infected people who are vulnerable to poverty are more likely to engage in high-risk behaviour to cope with the poverty, which in turn makes others susceptible to HIV infection. In a South African national survey, two-thirds of the respondents reported a drop in household income as a result of HIVrelated illness, including the direct loss of earners. As was also found elsewhere in sub-Saharan Africa, households reported increased expenditure on health, thereby diverting income away from other requirements. Severe illness and death have been found to vary according to the initial economic strength of the households that experience an HIV-related shock. Deaths of young adults from natural causes (including those from HIV/AIDS) had a negative impact on the growth in income of all households over a five-year period, but especially on those households that were initially modestly well-off.

Lack of education perpetuates the cycle between HIV/AIDS and poverty, often arising from decisions concerning schooling, child-bearing, finances and unemployment. A number of studies have measured some of these negative outcomes, which suggest that there are significant inter-generational consequences of household coping strategies.

While HIV/AIDS has a negative impact on education, it is also through education that appropriate mitigation initiatives can be implemented. The integration of HIV/AIDS education and life-long skills programmes in the school curricula can be an effective way of influencing behavioural changes in children from an early age. About 40 per cent of the HEIs in South Africa had different types of units engaged in HIV/AIDS research. Such units should conduct strategy-relevant research on HIV/AIDS and poverty alleviation, with outputs that can inform policy and other appropriate interventions. HIV/AIDS should also be integrated in the academic curricula. At the same time, the establishment of community-based sustainable development projects to empower communities could enable individuals and households to overcome the poverty impact of the disease.

The author wishes to acknowledge contributions to this article by Professors Julian May and Alan Whiteside of the University of KwaZulu-Natal.

Notes

1 D. Gachui, The Impact of HIV/AIDS on Education Systems in the Eastern and Southern African Region, UNICEF Report, 1999. 
2 C. L. Risley and L. J. Drake, Impact of HIV and AIDS on Education in the Greater Mekong Sub-Region, Workshop Presentation, Siem Reap, Cambodia, 2007.

3 HIV Prevelance and Related Factors-Higher Education Sector Study, South Africa 2008-2009, ISBN: 978-0-62046068-2, 2010.

4 T. Barnett and A. Whiteside, AIDS, Public Policy and Child Well-Being (Edited by Giovani Andrea Cornia), Chapter 11, UNICEF Innocenti Research Centre, 2007. 